are less likely to produce reactions in certain high risk patients such as those with asthma, cardiac or renal failure, or a history of such reactions (19 March, p 809). He states, quite rightly, that these media are still considerably dearer than the older agents but does not mention the quantity necessary to produce adequate radiographs.

Using only half the currently recommended dose $(25 \mathrm{ml}$ instead of $50 \mathrm{ml}$ ), we have shown that in most patients this amount produces diagnostically acceptable urograms. ${ }^{1}$ Our conclusion was that if this regimen is followed it should prove possible to use the safer media for all patients and that although this would cost more than at present it should prevent the rare serious complications including the occasional death.

\section{MYer Goldman}

BRIAN EYFS

Departments of Radiology,

Fazakerley and Walton Hospitals,

Liverpool L9

1 Eyes BE, Goldman M, Nixon TE, Scally J, Brown A. Low dose low osmolar intravenous urography. Clin Radiol 1987;38: 403-5.

\section{Early growth in diabetic pregnancy}

SIR,-Dr Minna Bloch Petersen and colleagues (27 February, p 598) seek to show that delayed fetal growth in early pregnancy, which they report as being more common in the offspring of diabetic women, is a cause of developmental delay at age 4 .

In drawing this conclusion, however, they ignore a crucial part of their own data-namely, that only $5 \%$ of the diabetic mothers were educated to college standard compared with $18 \cdot 6 \%$ of the non-diabetic women. Since the only significant difference between the Denver test scores of the two groups of children was in language and speech development, it seems at least as likely that this was related to levels of sophistication in language use in the mothers as it was to intrauterine growth delay. It is, of course, true that there was apparently a difference within the diabetic group between those children in whom growth was delayed and those in whom it was not; the numbers of children in these two groups who failed the Denver test, however, were small (eight and two respectively), so that the probability of a type 2 error must be high if some other factor, such as maternal educational level, is operating.

Royal Liverpool Hospital,

Liverpool L7 8XP

ROGER A FISKEN

AUTHOR'S REPLY,-Dr R A Fisken is right in his remarks on the educational difference between diabetic and non-diabetic mothers $(2.4 \%$ and $18.6 \%$ educated at college level respectively).

In our study we found that as a group the children of diabetic mothers scored only slightly (and not significantly) worse than those of nondiabetic mothers. Secondly, the results of the Denver developmental screening test were not associated with the level of education of the mothers. Thirdly, the children of diabetic mothers with normal early fetal growth had scores very similar to those of the children of non-diabetic mothers, and no significant difference was found in language and speech development (the difference in the educational level of the mothers in the two groups being the same as mentioned above) Finally, the poor performance in the Denver developmental screening test in the diabetic group was apparently confined to those children who had been small in early fetal life. Only $67 \cdot 7 \%$ of these children had normal test scores and $23.5 \%$ failed in language and speech, compared with $92 \%$ and
$4 \%$ respectively of the children with normal discuss their data in the context of prevention by early fetal growth. The educational level of the two groups of diabetic mothers did not differ significantly.

We are well aware of the small number of children failing in language and speech and are aware that factors other than the mother's level of education may be operating-for example, different types of kindergartens. The overall test result of the two diabetic groups based on 34 and 50 children indicates, however, that early fetal growth delay may influence later development.

MinNa Bloch Petersen

Rigshospitalet,
Copenhagen $\emptyset$,

Copenhagen $\emptyset$
Denmark

HIV infection: risks of false positive serology

SIR,-Professor A A Glynn and Dr P P Mortimer (5 March, p 714) are right to emphasise that most commercially available HIV antibody tests are both highly sensitive and highly specific. If two different systems are used the risk of a false positive is about 1 in 40000 and if three different systems are used about 1 in 1 million.

Nevertheless, most virologists concerned in rubella antibody screening have encountered patients who have been reported as having rubella antibodies but have subsequently acquired rubella in pregnancy. In most cases this error has not been due to any failure of test systems or to loss of rubella antibodies but has been the result of other factors. ${ }^{12}$ These include, for example, incorrect labelling of blood containers in outpatient departments, technical errors, perhaps due to the interruption of a busy medical laboratory scientific officer performing the test, or even the issuing of an incorrect report due to a clerical error.

In view of the serious medicolegal consequences as well as the distress which may result from a false positive HIV test, we recommend that the risks should be minimised by issuing only a preliminary report when a serum sample is found to be positive by three tests. A final report can then be issued when the results have been confirmed by testing an additional serum sample from the same patient.

Since we routinely perform tests three times a week (or immediately in an emergency) and as clinicians can readily make arrangements to have their patients retested within a few days, our system need not result in there being undue delay before a final report is issued.

Felicity Nicholson JENNIFER M BEST J E BANATVALA

Department of Virology,

St Thomas's Hospital,

St Thomas's Hospit
London SE1 7EH

1 Best JM, Welch JM, Baker DA, Banatvala JE. Maternal rubella at St Thomas' Hospital in 1978 and 1986: support for augmenting the rubella vaccination programme. Lancet 1987;ii:88-90.

2 Miller CL, Miller E, Waight PA. Rubella susceptibility and the continuing risk of infection in pregnancy. $\mathrm{Br}$ Med $\mathcal{f}$ continuing risk

\section{The use of varicella vaccine in Britain}

SIR,-Drs Carol Joseph and Norman Noah provide valuable information on the clinical impact of varicella in Britain (5 March, p 673). They rightly point out that varicella accounts for a higher mortality than mumps, which we are about to attempt to prevent with the combined measlesmumps-rubella vaccine, but seem reticent to

\section{vaccination.}

We agree that a mass vaccination programme using the live varicella vaccine cannot be advocated until the questions of safety and long term efficacy have been resolved. A cost-benefit analysis ${ }^{1}$ has shown a benefit ratio of 7:1 for mass vaccination in the USA, but this benefit was mainly derived from costs to the family arising from the home care of sick children, not savings on medical costs. Since social conditions in Britain are different the financial argument will be strong only if the cost of the vaccine is comparable with that of other vaccines.

The most interesting dilemmas for licensing authorities relate to the long term effects of the vaccine on the epidemic pattern of varicella and on herpes zoster. Recent reports have shown that the vaccine virus can become latent and cause zoster, ${ }^{2}$ even in healthy vaccinees, ${ }^{3}$ although probably less frequently than wild type virus. More intriguingly, vaccination may not always protect from superinfection with wild type varicella zoster virus, which later can cause zoster. ${ }^{2}$ Paradoxically, only the experience gained through more general use of the vaccine will provide the necessary information about its long term effects on varicella and zoster.

The case for vaccination of immunocompromised patients is totally different. This is a steadily increasing group of patients who carry a high risk of life threatening complications associated with varicella. ${ }^{4}$ Undoubtedly, it is preferable to prevent these complications by vaccination rather than to rely on postexposure prophylaxis and treatment with zoster immune globulin or acyclovir. In fact, the vaccine is also effective for postexposure prophylaxis up to four days after contact. ${ }^{5}$

The vaccine has now been used in immunocompromised patients for over 10 years and has proved to be both safe and effective. ${ }^{6}$ Our own experience with this vaccine ${ }^{7}$ in paediatric oncology patients is that individual responses vary greatly but even in those with poor responses the vaccine appears to confer considerable protection. Good antibody concentrations have been maintained for over six years in some of our vaccinees after a single vaccine dose, although about $40 \%$ have shown poor or rapidly waning responses. Regular monitoring of immunity, combined with a booster vaccination, is therefore necessary.

It may not be a perfect vaccine but it is the best we have, and, while mass vaccination cannot be advocated on present evidence, there is no doubt that selected high risk groups would greatly benefit from this vaccine, particularly children with malignancies. The problem for British paediatricians who manage immunocompromised children is that the vaccine is not freely available here. The relevant authorities should give serious thought to licensing the varicella vaccine for selective use, as is done in several European countries and shortly will be in the United States.

H O KANGRO R B HEATH

Department of Virology,

St Bartholomew's Hospital,

London EC1A 7BE

1 Preblud SR, Orenstein WA, Koplan JP, Bart KJ, Hinman AR. A benefit cost analysis of a childhood varicella vaccination benefit cost analysis of a childhood varicella vaccing
programme. Postgrad Med f 1985;61(suppl 4):17-22.

2 Lawrence R, Gershon AA, Holzman R, Steinberg SP. The risk of zoster after varicella vaccination in children with leukemia. N Engl f Med 1988;318:543-8.

Plotkin SA. Hell's fire and varicella-vaccine safety. $N$ Engl $\mathcal{F}$ Med 1988;318:573-5. 1986;78(suppl):728-35.

5 Takahashi M, Hayakawa Y, Shiraki K, Yamanishi K, Asano Y, Ozaki T. Attenuation and laboratory markers of the Oka-strain
varicella-zoster virus. Postgrad Med f 1985;61(suppl 4):37-46. 6 varicella-zoster virus. Postgrad Med f 1985;61(suppl 4):37-46. varicella vaccine. Postgrad Med F 1985;61(suppl 4):113-20.
Preblud SR. Varicella: complications and costs. Pediatrics 
7 Heath RB, Malpas JS, Kangro HO, Ward A, McEniery JM, Kingston JE. Efficacy of varicella vaccine in patients with solid tumours. Arch Dis Child 1987;62:569-72.

\section{Plastic insulin syringes}

SIR,-Nine years ago Greenough et al pointed out how seldom diabetics became infected by injecting themselves daily with insulin using the same disposable syringe on several occasions, sometimes for several weeks, simply by covering the needle (attached to the syringe) with its cap and leaving the syringe in the refrigerator. ${ }^{1}$ They found no evidence of infection even when the syringe was used for up to two months.

In the correspondence that followed Oli, from Nigeria, reported that his diabetics, who could often not afford glass syringes, used their plastic syringes on average for a month, but as few had refrigerators he advised them to put syringe and needles in a clean covered container or pot in a hole in the ground, and since 1974, when he started the diabetic clinic, he had seen no infections. ${ }^{2}$ In 1985 Bloom detailed the advantages of plastic over glass syringes for insulin injections, ${ }^{3}$ and two years later, after a long campaign by the British Diabetic Association, they became available on general practitioners' prescriptions.

Drs W D Alexander and R Tattersall have now pointed to the great and unnecessary expense of diabetics using plastic syringes once only. Having run two separate diabetic clinics in London weekly for many years in the past, I know that patients use their disposable plastic syringes over long periods without any trouble. It does seem that here, where the same diabetic person uses the same syringe daily, the advice of the Department of Health and Social Security and the National Pharmaceutical Association to use these syringes only once is unnecessary and costly to a National Health Service trying hard to economise.

London W1N IAN

F DUdLEY HART

1 Greenough A, Cockroft PM, Bloom A. Disposable syringes for insulin injection. $\mathrm{Br}$ Med f 1979; i: 1467-8.

2 Oli JM. Disposable syringes for insulin injection. $\mathrm{Br}$ Med $\mathrm{J}$ 1979;ii:273-4.

3 Bloom A. Syringes for diabetics. Br Med f 1985;290:727-8.

SIR,-Drs W D Alexander and R Tattersall (26 March, $p$ 877) claim that insulin preparations are self sterilising because they contain a preservative. That this is not universally so has been described previously ${ }^{12}$ and is further illustrated by the following event.

A 43 year old diabetic was admitted to hospital with multiple large subcutaneous abscesses of the thighs and buttocks, which had developed over three weeks at the sites where she injected insulin. The abscesses were incised under general anaesthesia, and the pus thus liberated yielded a heavy growth of Streptococcus faecalis on culture.

The patient's insulin phials were examined bacteriologically 12 days later. Both phials in current use yielded no organisms by direct plating on solid media, but one (a mixed insulin zinc suspension containing methyl-p-hydroxybenzoate as preservative) yielded $S$ faecalis and Bacteroides fragilis when injected into blood culture media.

Small numbers of organisms can thus survive for prolonged periods in some insulin preparations, and those which contain methyl-p-hydroxybenzoate should not be regarded as self sterilising. Good practice dictates that any multidose container of solutions for injection should be entered only with a sterile needle; otherwise skin and potentially pathogenic environmental organisms may be carried into the phial and persist or multiply to form a reservoir of infection.

Plastic insulin syringes cannot be resterilised in the home, so logically they must be used only once and then discarded if episodes of this nature are to be reliably prevented, especially when using insulin preparations preserved with methyl-p-hydroxybenzoate.

H J BLACK

Department of Pathology

Huddersfield Royal Infirmary

Huddersfield HD3 3EA

1 Collins BJ, Spence BK, Richardson SG, Hunter J, Nelson JK. Safety of reusing disposable plastic insulin syringes. Lance Safety of reusin

2 Allwood MC. Re-use of plastic insulin syringes. Lance 1983; i:712-3.

\section{Adult epiglottitis}

SIR,-We were surprised at the antibiotics chosen for the initial blind treatment of the adult with epiglottitis described by Dr Shaheen Mehtar and others (19 March, p 827) (benzylpenicillin and erythromycin), particularly as the patient's condition was severe enough to require intubation.

In childhood epiglottitis the causative organism is usually Haemophilus influenzae type b. The adul condition can be caused by a wider range of organisms, but haemophilus is still common (others include pneumococcus). Apart from the well known increased susceptibility to pneumococcal infection, a patient who has had a splenectomy is also at increased risk of infection by haemophilus and meningococcus.

Current teaching suggests the use of ampicillin or chloramphenicol, or both, as the first line antibiotic treatment of epiglottitis while the bacterial culture results are awaited. ${ }^{2}$ Despite its recognised complications chloramphenicol is normally advocated in life threatening situations owing to the increasing prevalence of ampicillin resistant strains of haemophilus $(11.4 \%$ in the United Kingdom in $1981^{3}$ ). Cefuroxime is active against these strains and is a suitable alternative initial treatment. Although erythromycin has been considered to be active against Haemophilus influenzae, it has a minimum inhibitory concentration of $1 \cdot 0-8 \cdot 0 \mu \mathrm{g} / \mathrm{ml}$, whereas chloramphenico has a value of $0.5 \mu \mathrm{g} / \mathrm{ml}$, cefuroxime $0.5 \mu \mathrm{g} / \mathrm{ml}$, and ampicillin $0 \cdot 25 \mu \mathrm{g} / \mathrm{ml}$.

In both children and adults epiglottitis is a serious condition which can be fatal. Though it is completely curable, any delay in diagnosis and treatment may result in sudden, potentially fata respiratory obstruction. ${ }^{5}$ As well as humidification and airway support the patients require treatment with adequate doses of intravenous antibiotics appropriate to the likely infecting organism.

J E DAVIES

Department of Otolaryngology,

D G JOHN

University Hospital of Wales,

Cardiff CF4 4XW

1 Weatherall DJ, Ledingham JGG, Warrell DA, eds. Oxford textbook of medicine. Vol 1. 2nd ed. Oxford: Oxford University Press, 1987:5.620.

2 Kucers A, Bennett NMcK, eds. The use of antibiotics. 4th ed. London: Heinemann, 1987:763.

3 Philpott-Howard J, Williams JD. Increase in antibiotic resistance in Haemophilus influenzae in the UK since 1977: report of a study group. Br Med f 1982;284:1597.

4 Garrod LP, Lambert HP, O'Grady F, eds: Antibiotic and chemotherapy. 5th ed. Edinburgh: Churchill Livingstone, 1981:275.

5 Gerrish SP, Jones AS, Watson DM, Wight RG. Adult epiglottitis BrMed f 1987;295:1183-4.

AUTHORS' REPLY,-We concur entirely with Drs Davies and John about the choice of antibiotics in acute epiglottitis. Our district antibiotic policy recommends the use of intravenous chloramphenicol as first line treatment in epiglottitis. In this case, however, the emergency action taken was based entirely on clinical assessment of a patient who had undergone splenectomy and was susceptible to pneumococcal and staphylococcal infections in the first instance (there had been no consultation with the clinical microbiologists at that time). The priority was to relieve the obstruction and stabilise the patient. Within 12 hours the patient had started to improve and change of antibiotic treatment was considered unnecessary.

The confines of a brief report did not allow lengthy discussion on antibiotic use; we concentrated on the presentation of acute adult epiglottitis, a rare condition in itself, due to a rare organism.

S MEHTAR

L BANGHAM

Microbiology Department,

North Middlesex Hospital,

London N18 1QX

\section{Private nursing home care}

SIR, - We welcome the contribution made by Professor W J MacLennan (12 March, p 732). Private sector residential and nursing home care now provides care for $4 \%$ of all those aged over 65 and $20 \%$ of those over 85 in the United Kingdom. However, this rate of institutional care is low compared with that in other Western societiesfor example, in France and Switzerland more than $6 \%$ of the over 65 s occupy similar accommodation and in Australia $14 \%$ of the over 75 s are in this type of care-a figure twice that for the United Kingdom.

By 1997 it is projected that there will be more than 1 million people over the age of 85 in the UK. Since admission to long term care correlates with age, even at current rates of provision, expansion must occur somewhere. Limited growth has already occurred since 1976 , when there were 71.5 places in local authority and independent homes for every 1000 people over 75 years; by 1986 there were 80 such places.

Although the total figure has risen since the $1960 \mathrm{~s}$, there has been a reduction in the number of long stay beds within the National Health Service. There has been a slight increase in the number of local authority places, but the most striking change has been the increase in private sector provision since 1980 . In 1986 less than half of all expenditure on long term care of the elderly (and the physically handicapped) was actually supplied as well as financed by the public sector, ${ }^{2}$ reflecting previous state underprovision. With the continuing contraction of long stay NHS facilities and little change in local authority provision the private sector currently meets the shortfall. The private sector has the advantage of rapidly responding to demand, in contrast to the NHS.

The Griffiths report, however, may allow this continuing expansion to become more ordered since if the report is implemented local authority social services departments would be the agencies through which care could be bought from any sector, the client being assessed and placed in the accommodation deemed most suitable. Nevertheless, this concept hinges primarily on the politica will to devolve power and resources to the local level, which is in some doubt.

However it is organised, there will remain problems with the continuing expansion of the private sector, of which ensuring quality is the most important. There is also the problem of maintaining continuity of care as raised by $\mathrm{Dr} J \mathrm{~K}$ Bynoe (12 March, p 788), although this could be 